\title{
Numerical Study Supercavitating of the Pump
}

\author{
Vladimir A. Kulagin* \\ Siberian Federal University \\ 79 Svobodny, Krasnoyarsk, 660041, Russia
}

Received 14.02.2015, received in revised form 18.05.2015, accepted 22.06.2015

The problem of effective supercavitating (SC) pump is solved, and optimum load distribution along the radius of the blade is found taking into account clearance, degree of cavitation development, influence of finite number of blades, and centrifugal forces. Sufficient accuracy can be obtained using the equivalent flat SC-grid for design of any SC-mechanisms, applying the "grid effect» coefficient and substituting the skewed flow calculated for grids of flat plates with the infinite attached cavitation caverns. This article gives the universal design method and provides an example of SC-pump design.

Key words: Lagranian coefficient, base line vortex theory, supercavitating grids theory, equivalent grid, grid effect.

DOI: $10.17516 / 1999-494 X-2015-8-5-669-674$.

\section{Численное исследование}

суперкавитирующего насоса

\author{
В.А. Кулагин \\ Сибирский федеральный университет \\ Россия, 660041, Красноярск, Свободный, 79
}

Решена задача об эффективном СК-насосе и найдено оптимальное распределение нагрузки вдоль радиуса лопасти с учетом величины зазора, степени развития кавитации, влияния конечного числа лопастей и центробежных сил. Показано, что с достаточной точностью можно получить решение, используя эквивалентную плоскую СК-решетку для проектирования любых СК-механизмов, применяя коэффициент «эффекта решетки» и подставляя перекос потока, рассчитанный для решетки плоских пластин с бесконечными прикрепленными кавитационными кавернами. В статье изложен универсальный метод проектирования и представлен пример расчета конструкичии CK-насоса.

Ключевые слова: переходной коэффициент, вихревая теория, базовая линия, теория суперкавитируюших профилей, эквивалентная решетка, эффект решетки.

(C) Siberian Federal University. All rights reserved

* Corresponding author E-mail address: v.a.kulagin@mail.ru 


\section{Introduction}

The one effective application of the cavitation technology are supercavitating pumps (SC-pumps), which have advantages in variety of industrial processes $[1,2]$. The basics for calculation of any cavitating equipment, working in the presence of developed cavitation, are their geometry parameters and hydraulic characteristics, i.e. the solution must contain the flow velocity and pressure distribution, and cavitation bubble's dimensions. For the given flow rate and net head, the design of the SC-pump's impeller requires calculation of its profile's geometry, the number of blades etc., as well as calculation of its rotation velocity, axial velocity etc.; but in addition, the design is complicated by generation of the cavity with required length, the number and size of the cavitation bubbles.

\section{Load Distribution}

Calculation algorithm of SC-pumps is based on the solution of a supercavitating flow around a blade's element or equivalent flat blades grid [3]. In the first stage of the design of a rotary equipment, the best load allocation along the blade's radii is calculated. This factor would ensure the required net head with minimal energy losses.

The best load allocation along the axis of a real SC-pump's blade is found by the formula obtained by the method of successive approximations:

$$
\frac{\mathrm{d} C_{P}}{\mathrm{~d} \bar{r}}=\frac{4 L\left(1-\varepsilon \operatorname{tg} \beta_{i}\right) K_{Z} \bar{r}}{\operatorname{tg} \beta_{i}^{2}+K_{\varepsilon}+1}
$$

where $C_{P}=\frac{2 \Delta P}{\rho v_{0}^{2}}-$ the static pressure coefficient; $H=H_{+\infty}-H_{-\infty}-$ the pressure generated by the SC-pump; $\varepsilon=C_{x} / C_{y}=0,075 \div 0,100$ - reverse quality of the SC-profile and composition of the grid (first approximation); $K_{Z}=K_{Z}\left(\lambda_{1}, K_{\varepsilon}, K_{\mu}, Z, \ldots\right)$ - amendment to the limited number of blades; $\bar{r}=r / R$ - relative radius of the blade; $r, R$ - the current and the outer radius of the blade respectively; $\beta_{i}$ - the angle of entry of the relative speed with influence of the inductive speed $\left(\operatorname{tg} \beta_{i}=v / \omega_{r}\right.$ see Fig. 1); $K_{\varepsilon}=F_{S C} / F_{C H}$ - the relative gap; $F_{C H}, F_{S C}$-square of the channel and SC-impeller respectively; $L=L\left(K_{\varepsilon}, \lambda_{1}, \lambda_{0}\right)-$ the Lagrangian coefficient obtained from the solution of variational problem, which computed by the formula:

$$
\begin{aligned}
& L=\frac{2\left(\lambda_{i} / \lambda_{0}-1\right)}{\frac{1+\lambda_{i}}{\lambda_{i}^{2}+K_{\varepsilon}+1}-\frac{K_{\varepsilon} \lambda_{i}^{2} \ln \left[1+\left(K_{\varepsilon}+1\right) 1 / \lambda_{i}^{2}\right]}{\left(K_{\varepsilon}+1\right)^{2}}} \\
& \lambda_{i}=\operatorname{tg} \beta_{i} \bar{r}=\left.\operatorname{tg} \beta_{i}\right|_{r=R}=\frac{v_{0}+w_{a s}^{*}}{\omega r-w_{\tau s}^{*}}
\end{aligned}
$$

where $\lambda_{0}=v_{0} / \omega_{r}$ - the relative pace at the pump's inlet; $v_{0}, \omega_{r}-$ the axial and circumferential speed of fluid relative to an element of the blade at the pump's inlet; $w_{a s}^{*}, w_{\tau s}^{*}-$ the axial and circumferential speed at the blades (см. puc. 1). By integrating these values $d C / d \bar{r}$ along the radii of the blade, we find the coefficient of static pressure in the first approximation.

The next step in calculation of the SC-pump is to define the spatial characteristics of the blade grid for the given radius, which would ensure maximum value of the quality $k=C_{y} / C_{x}$ for the load on the radius, obtained in first stage, and taking into account the conditions of strength.

The study dealt with the SC-grid made of the following profiles: flat plate; low wrap profile $\bar{f}=f / b \leq 0,03$; circle's arch profile $(\bar{f} \leq 0,04)$; concave profile, described by an equation of second, 
third and fifth order $(\bar{f} \leq 0,06)$; profile with square load allocation $(\bar{f} \leq 0,1)$. Ranges of parameters for calculation were chosen as follows: relative length of the cavity $\bar{L}_{C}=L_{C} / B_{C}=1,5 \div 20$ (length to width ration); relative curvature of profiles $\bar{f}=0 \div 0,1$; relative grid density $b / \tau=0.5 \div 1.5^{\circ}$; stem angles gratings $\beta=10 \div 75^{\circ}$; angles of attack $i=0 \div 20^{\circ}$.

In Fig. 1, 2 and 3 show the hydrodynamic characteristics of SC-grids for flat plates and curved profiles with a rectangular distribution of pressure along the chord $\varepsilon=\varepsilon\left(b / \tau, \beta_{0}, C_{y}\right)$. Here $\varepsilon=C_{x} / C_{y}==f\left(b / \tau, \beta_{0}, C_{y}, \beta_{i}, \chi\right), \bar{L}_{C}=L_{C} / B_{C}==f\left(b / \tau, C_{y}, \beta\right)$.

Design calculation of SC-pumps is based on the "base line" vortex theory, the theory of SC-grids, as well as on the method of equivalent SC-grid. The calculation is carried out in two phases. First determine the optimum load distribution along the radius of the blade on the desired characteristics of SC-pump: static pressure of $H_{S}$, the flow $Q$, the rotational speed $n$, or the diameter blade's outer $D$ (for a given $D$ the unique value $n$ can be evaluated among the several numbers $n$ ).

\section{Profiling}

Once the optimum distribution of circulation (load) is found, one proceed to the choice of structural elements of the blades suitable for this distribution, and profiling in accordance with the strength conditions and optimum for dynamic quality of profiles.

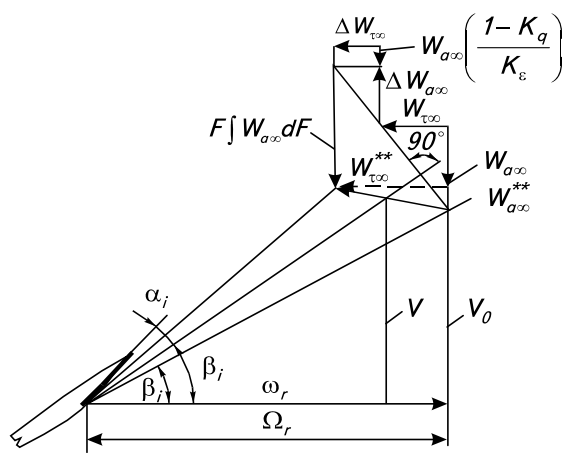

Fig. 1. Triangles of flow velocities, flowing on the blades of the SC-grid with an arbitrary gap

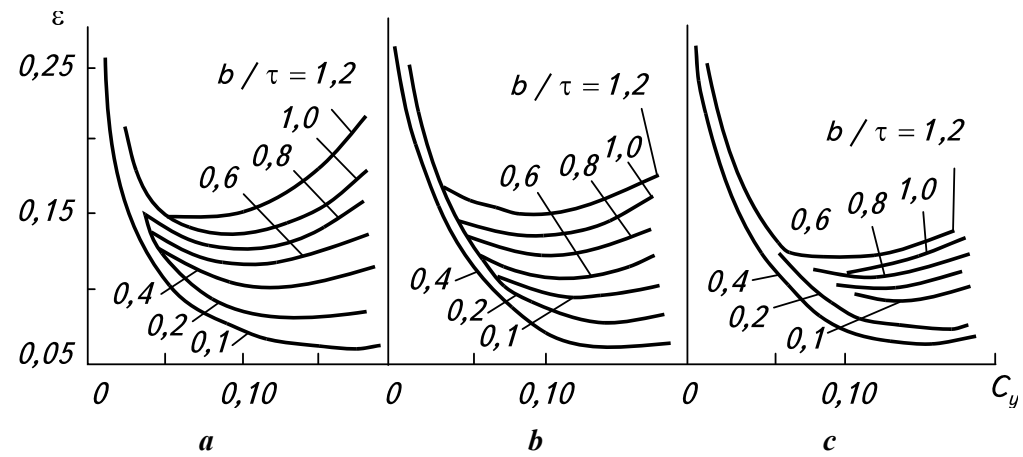

Fig. 2. Reverse quality factors $\varepsilon=\varepsilon\left(b / \tau, \beta_{0}, C_{y}\right)$ for SC-grids of flat plates with $\bar{L}_{K} \rightarrow \infty, \chi \rightarrow \chi_{\min }$; where $\mathrm{a}-\beta_{0}=15^{\circ} ; \mathrm{b}-\beta_{0}=30^{\circ} ; \mathrm{c}-\beta_{0}=60^{\circ}$ 


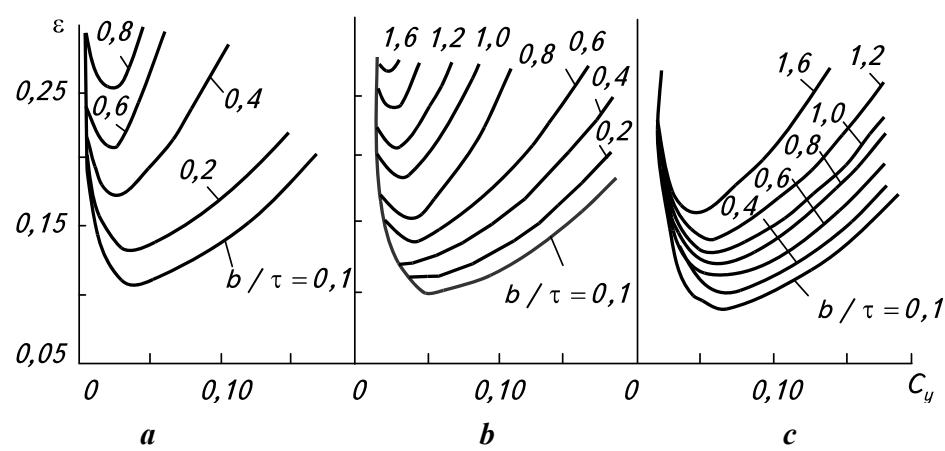

Fig. 3. Reverse quality factor $\varepsilon=\varepsilon\left(b / \tau, \beta_{0}, C_{y}\right)$ for SC-grid made of curved profiles with the rectangular distribution of pressure along the chord for $\bar{L}_{K} \rightarrow \infty, \chi \rightarrow \chi_{\text {min }}$; where $\mathrm{a}-\beta_{0}=15^{\circ} ; \mathrm{b}-\beta_{0}=30^{\circ} ; \mathrm{c}-\beta_{0}=60^{\circ}$

Optimal load distribution along the blade's radius is found by the formula (1). Expressing the profile drag by the multiplier $\left(1-\varepsilon \operatorname{tg} \beta_{i}\right)$, limit of the number of blades by $K_{Z}$, and calculating the Lagrangian $L$ from equation (2) by the method of successive approximations, find the distribution of load factor along the blade's radius of a real SC-pump (1).

On the basis of the calculations one can build diagrams to determine the inductive dynamics $\lambda_{i}$ of optimal SC-pump with an arbitrary gap and the degree of cavitation development for the given finite number of blades for the stated values of $C_{P}, \lambda_{o}$ and strength (parameter $t$ ) [1].

In the second stage of calculation chose structural elements of blades that provide found circulation and distribution of the induced speeds. Using the theorem of Zhukovskiy for lifting force on element of the blade $d y=p v_{i} \Gamma d r$, and the following expression

$$
\mathrm{d} y=C_{y} \frac{\rho v_{i}^{2}}{2} b \mathrm{~d} r
$$

write down the equation for coupling of the blade and the flow:

$$
\Gamma=\frac{1}{2} C_{y} v_{i} b
$$

Substituting (3) into the expression for the static head pressure lightly loaded SC-pump

$$
Q H_{S}=v_{0} \rho \omega \int_{r_{S}}^{R} r \Gamma K_{\mu} \mathrm{d} r
$$

obtain

$$
\mathrm{d} H_{S}=\frac{\rho v_{0 \omega}}{v_{0} \pi R_{C H}^{2}} z C_{y} \frac{b}{2} v_{i} K_{\mu} r \mathrm{~d} r
$$

Taking into consideration that

$$
v_{i}=\frac{\omega r-w_{\tau s}^{*}}{\cos \beta_{i}}=\frac{v_{0}-w_{a s}^{*}}{\sin \beta_{i}}
$$




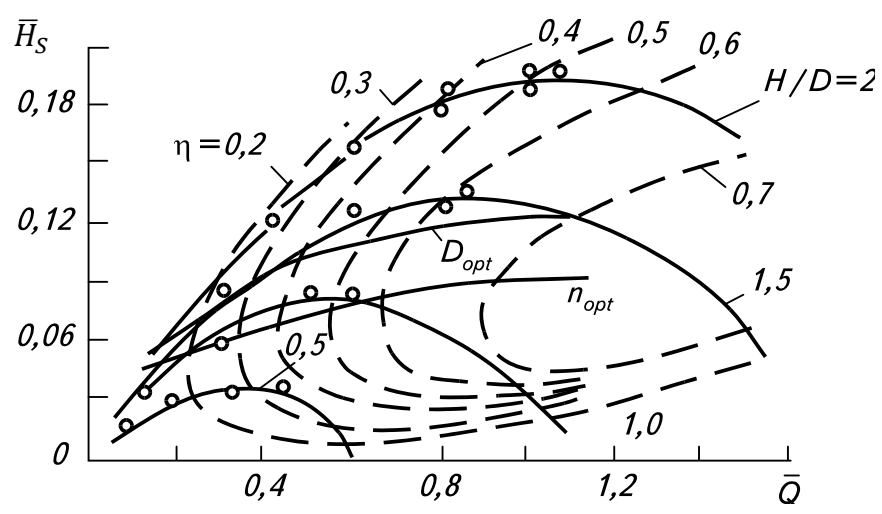

Fig. 4 Universal chart of hydrodynamic characteristics for SC-pumps working under developed cavitation with $\bar{H}_{S}=f(Q), \bar{H}_{S}=\frac{H_{S}}{\rho n^{2} D^{2}}=f\left(H / D, b / \tau, \chi, K_{\varepsilon}\right)$

then from (3) derive the formula to determine the hydro-mechanical parameter of SC-pump's blade:

$$
C_{y} \frac{b}{\tau}=\frac{1}{2} \cdot \frac{\lambda_{0}}{\bar{r}^{2} K_{\varepsilon} K_{\mu}} \cdot \frac{\sin \beta_{i}}{1+w_{a s}^{*}} \cdot \frac{\mathrm{d} C_{P}}{\mathrm{~d} \bar{r}}
$$

It should be noted that in the charts of hydrodynamic characteristics of SC-grids (see Fig. 2, 3), one can add the curves of equal values of the parameter $C_{y} b / \tau$. Thus, defining for each radius the value $\beta_{i}$ and parameter $C_{y} b / \tau$ for a set of SC-grids, one can choose the grid that has the lowest inverse quality $\varepsilon_{\text {min }}$.

Then, using a method of the equivalent SC-grid [1], for known $b / \tau, \beta_{i}, L_{K}$, find a factor which takes into account the influence of the "grid effect" without the skewed flow $J_{P}=J_{P}\left(b / \tau, \beta, L_{K}\right)$. Similar calculations for grids of curved profiles with arbitrary length of the cavern show that $J_{P}$ is the factor influencing the "grid effect" (for grid density $b / \tau>0.6$ ). But the "grid effect practically does not depends on the curvature $f$, profile's form and the cavern length $L_{K}$. The vortex base line theory can be used to find the stream skew $\Delta \alpha_{i}=\Delta \beta_{i}$ near the impeller.

By $C_{y}$ and $J_{P}$ determine the setup angle of the blade on each radius $\varphi$ :

$$
C_{y_{i m p}}=J_{p}\left(\frac{\partial C_{y}}{\partial \alpha}\right)_{s a p} \alpha_{i}
$$

where the designation "imp" - impeller; "sap" - stand-alone profile. Writing $\alpha_{i}=\varphi-\beta_{i}$ gives

$$
\varphi=\frac{C_{y}}{J_{p}}\left(\frac{\partial C_{y}}{\partial \alpha}\right)_{s a p}+\beta_{i}
$$

Therefore $H / D=\pi \bar{r} \operatorname{tg} \varphi$. For convenience, the calculations of design write down in a table form. Based on the described methods, calculation of the generic diagrams of hydrodynamic characteristics of SC-impellers can be done.

The Fig. 4 illustrates one such diagram of supercavitating regimes for SC-pump's impellers ( $b / \tau=1 ; \chi=0,25 ; K_{\varepsilon}=0,96$; profile is a wedge-shaped flat plate) that are used for simultaneous pumping and processing of the working fluids [1]. 


\section{Conclusion}

In its current state, this method allows design of rotary equipment, which simultaneously pumps the medium, and uses effects of cavitation on the pumped medium (SC-pump). The highly turbulent cavitation bubbles collapse, observed under the developed cavitation condition, have numerous applications $[1,4]$. For the given conditions and working fluids, designer should be aware of the negative and the positive consequences of cavitation effects, especially for the extremal case - supercavitation.

\section{References}

[1] Ивченко В.М., Кулагин В.А., Немчин А.Ф. Кавитационная технология: монография / ред. акад. Г.В. Логвинович. Красноярск: Изд-во КГУ, 1990. 200 с.

[2] Демиденко Н.Д., Кулагин В.А., Шокин Ю.И. Моделирование и вычислительные технологии распределенных систем: монография / ред. чл.-корр. РАН А.М. Федотов. Новосибирск: Наука, 2012. 424 с.

[3] Кулагин В.А. Вильченко А.П., Кулагина Т.А. Моделирование двухфазных суперкавитационных потоков / ред. В.И. Быков. Красноярск: КГТУ, 2001. 187 с.

[4] Kulagin V.A., Likhachev D.S., Feng-Chen Li. Modeling supercavitating flow in supercavitating pumps // Submitted to International Conference on Pumps and Fans (ICPF 2015), Hangzhou, China. 2015. 